\title{
Emotional awareness amongst middle leadership
}

\author{
Steve Lambert \\ Faculty of Education and Children's Services, University of Chester, Chester, UK
}

\begin{abstract}
Purpose - The purpose of this viewpoint paper is to explore middle leaders' ability to recognise emotions in the context of workplace research, and to propose measures that might support them in their role.

Design/methodology/approach - This paper combines a contemporary literature review with reflections from practice to develop more nuanced understandings of middle leadership. This paper applied the Geneva Emotional Recognition Test (GERT) to explore the level of emotional recognition of 86 individuals (teachers to headteachers (equivalent to school principals)).

Findings - The preliminary findings suggest that teachers and headteachers have higher levels of emotional recognition than middle and senior leaders. This paper subsequently argues that the task-orientated nature middle leadership compounds an individual's ability to engage effectively in relationship-orientated tasks. This explains why middle leaders scored lower on the GERT assessment. This is further inhibited by the anticorrelation in the brain's ability to deal with the task-positive network (TDM) and default mode network (DMN) processing functions where individuals operate in one neural mode for long periods.

Research limitations/implications - The viewpoint paper proposes a number of implications for middle leaders and suggests that middle leaders should proactively seek out opportunities to be engaged in activities that support the DMN function of the brain and subsequently the relationship-orientated aspects of leadership, for example, coaching other staff members. However, it has to be recognised that the sample size is small and further work is needed before any generalisations can be made.

Originality/value - This paper offers a contemporary review of the role of middle leaders underpinned by a preliminary study into individuals' ability to recognise emotions.
\end{abstract}

Keywords Middle leadership, Emotions, Neuroscience, TDM, DMN

Paper type Research paper

\section{Introduction}

Silva (2016) stated that leadership is one of those concepts that are very hard to define. More than four decades ago, Stogdill (1974) affirmed that "there are almost as many different definitions of leadership as there are persons who have attempted to define the concept" (p. 7). However, since the 1950s two distinct leadership roles have emerged, the task leader and the socio-emotional leader has been well documented in the leadership literature (Bales, 1958). These two roles have been conceptualised into theories such as transformational and transactional leadership (Bass, 1990). Transformational leadership principally focussing on building relationships with those whom leaders work. Whereas transactional leadership critically focusses on task achievement.

Leadership theorists such as McClelland (1961), Wofford (1970), Jago (1982), Vroom and Jajo (2007) and Henkel et al. (2019) have all become interested in developing strategies that would enable leaders to integrate these two fundamental leadership roles. For this paper, these will be referred to as task-oriented and relationship-oriented leadership in order not to attribute the approaches to one particular leadership theory. This ability of individuals to

(C) Steve Lambert. Published in Journal of Work-Applied Management. Published by Emerald Publishing Limited. This article is published under the Creative Commons Attribution (CC BY 4.0) licence. Anyone may reproduce, distribute, translate and create derivative works of this article (for both commercial and non-commercial purposes), subject to full attribution to the original publication and authors. The full terms of this licence may be seen at http://creativecommons.org/licences/by/4.0/legalcode

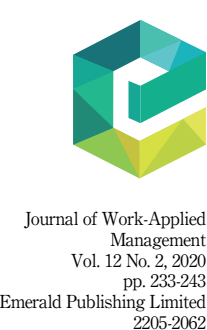

DOI 10.1108/JWAM-02-2020-0009 
JWAM

12,2

\section{4}

Table 1.

Levels of emotional awareness based on Lane et al. (1996) move effectively between task- and relationship-orientated activities is critical if leaders are to be adaptable and responsive to organisational challenges.

Hargreaves and Fink (2008) suggested that the challenge of functioning in either a task- or relationship-orientated role are compounded by the increasingly complex nature of educational leadership, changing student expectations and increased organisational financial constraint. These issues create a deficit of individuals who want to be leaders within schools and colleges. Frearson (2003) suggested that this void has been made worse by an ageing population, while Davies and Davies (2011) stated that the desire for a better worklife balance is also contributing to the lack of individuals seeking senior leadership. Both Gronn (2003) and Lynch et al. (2012) posit that leadership in education is greedy of an individual's time. While Gronn and Lucey (2006) state leadership occupies an ever-expanding space and requires sustained 24/7 levels of individual engagement.

In this paper, we will test to see whether an individuals' ability to recognise emotions is influenced by a range of factors, some of which are beyond their direct control. Most notably their position within the organisational hierarchy. This is compounded by the human brain's ability to switch on and off processing functions depending on the whether task- or relationship-orientated activities are being undertaken. However, it is beyond the scope of this paper to explore this as it would require functional imaging techniques to be employed.

\section{Literature review}

Emotional recognition and its importance

Hughes et al. (2005) suggest developing leaders with high emotional intelligence (EI) is key to individual and organisational success, especially in people-centred professions such as teaching. However, EI is just one facet of an individual's cognitive skills set, alongside personal (Gardner, 1983), social (Cantor and Kihlstrom, 1987) and practical (Sternberg, 1995) intelligence. For the purpose of this paper, the definition of EI will focus on a set of abilities concerning (1) accurately perceiving and expressing emotion, (2) using emotion to facilitate cognitive activities, (3) understanding emotions and (4) managing emotions for both emotional and personal growth (Mayer and Salovey, 1997; Mayer, et al., 2001). The first of these four abilities, perceiving emotions, commonly referred to as emotional recognition (ER) denotes the ability to identify and interpret emotions in faces, pictures, voices and cultural objects - including the capability to recognise our own emotions.

Subic-Wrana et al. (2011) conceptual model of the levels of emotional awareness (LEA) theory explains the disturbed processing of emotions based on a model of cognitiveemotional development through a series of levels (1-5). This is a development of Lane et al. (1996) model which applied this principle to the development of an individual to be aware of emotions. The change from a less to a more differentiated state of emotional awareness provides a more nuanced approach to emotional awareness. The range of emotions is summarised in Table 1.

\begin{tabular}{lll}
\hline Level & Emotional state & Example \\
\hline 1 & Bodily sensation & I would feel ill \\
2 & Action tendency & I would like to run away \\
3 & Single emotion & We both would be happy \\
4 & Blend of emotions & I would feel depressed but would be happy that my friend won \\
5 & Blend of blends of & I would feel disappointed. But if someone else won, I would be happy that it is \\
& emotions & my friend. My friend will be proud and happy, but also concerned about me
\end{tabular}


Recognising emotions represents a fundamental trait of EI, as it makes managing all other emotional information feasible. It is important to note that EI is just one of many traits that leaders should process, but given the people-centred nature of education, it is key to a successful learning environment (Madhar, 2010).

The question remains whether there is a positive correlation between higher levels of EI and better social relationships between children, their peers and their teachers. Meisler's (2010) research suggested that people with high EI receive a higher level of organisational justice than their peers and are subsequently more satisfied and committed to their jobs. This echoes the work by Zeidner et al. (2004), in which they state that EI is a crucial factor in determining success at work, as it is often associated with various EI dimensions such as empathy, optimism and conflict resolution. However, caution is needed, as these indicators alone are no guarantee of success. Simply that individuals are able to work more effectively as part of a team to enhance the organisation's goals (Schunk and Zimmerman, 1998). Sani (2009) reinforces this by stating that teachers with high social awareness and emotional recognition have well-developed social skills and can use these skills to nurture positive relationships with others. It does not correlate with the individual being a good teacher.

One cannot simply assume that successful teachers (however success is defined) will automatically become equally good leaders. While teachers work with individuals for a significant proportion of their day, that does not infer either that they have good at recognising emotions and as such will make good transformational leaders. Indeed personality differences could influence an individual's ability as a task- or relationshiporientated leader. However, Wall et al. (2017) suggest that there is extensive literature on the positive role that emotions play in at the personal, organisational and societal levels including in workplace job satisfaction.

While the importance of $\mathrm{EI}$ is recognised it does not address the question about whether $\mathrm{EI}$ is a learned trait. According to Goleman et al. (2013), EI comes from a different part of the brain to academic intelligence. Cognitive abilities such as language and mathematical skills reside in the neocortex, the largest and most developed part of the cerebral cortex, the outermost part of the brain, and is the most recent evolutionary addition to the human brain. $\mathrm{EI}$, on the other hand, relies largely on the longstanding deep emotional centres in the midbrain and is also linked to the prefrontal cortex, the brain's executive centre, just behind the forehead. This, Goleman et al. (2013) explain why levels of EI are independent in each person.

The move from teacher to instructional leader signifies a shift, initially into management (for this paper defined as maintenance under institutional or district regulation; Bush, 2007) then onto leadership. Unlike teaching which is people-centred and therefore an emotion-laden occupation, instructional leadership in schools today is more task-orientated and less peoplefocussed. Yet, teachers are leaders in their own right, as they are leading children in the classroom. It is therefore plausible to consider that the skills needed to lead children are the same that leaders use to lead the educational organisation.

Wakeman (2009) stated that there is little doubt that EI has a strong influence on the ultimate success or failure of a learning experience, as fundamentally, teaching and learning are inherently emotional (Mortiboys, 2005; Powell and Kusuma-Powell, 2010). This is due to all learning being emotionally dependent (Mortiboys, 2012). Ashkanasy and Dasborough (2003) argue that due to the innate role of a teacher, as a leader in the classroom, their emotions are infectious and that teachers, through this utilisation of EI, can create a classroom environment where students feel "valued, curious, safe, relaxed, engaged and motivated" (Mortiboys, 2012). Therefore, the success of any school is dictated by the skills and competencies of its staff members. According to Cheese (2008), this is because of the following reasons: (1) Talent generates high performance, which in turn attracts new talent and creates
Emotional awareness 
JWAM

12,2

the means to reward it; (2) Talent drives improvements in productivity, quality, innovation and customer [student] satisfaction.

Grobler and Diedericks (2008) noted that without talent, any industry is doomed. Within schools, there will be people already with high EI and some of these individuals will wish to progress into leadership and some will not. This is supported by research undertaken by Hays (2014), which suggested that only $11 \%$ of middle leaders aspire to move up the educational hierarchy. What is important, is that senior leaders need to be able to identify this $11 \%$ and harness their talents in order to develop future leaders of education. It is entirely possible that schools already have talented staff members with high levels of EI but are not managing and supporting them effectively. Davies and Davies (2008) stated that developing staff members must be part of a wider strategy and not simply as an approach to succession planning. This will help employees to perform their current jobs more effectively while preparing them for the next job on the career ladder (Paul, 2005).

Mayer et al. (2000) highlighted that EI also enables individuals to efficiently interpret and manage a social environment making a positive difference. This raises the question as to how schools select future leaders and what traits are looked for in prospective leaders. Furthermore, it is imperative that any training related to providing knowledge also allows for the building of skills and developing the traits needed for leaders and those who aspire to leadership to be adequately equipped to lead. Given the current climate of low staff retention and reluctance to progress up the hierarchical ladder (Hays, 2014), schools have to make the senior managerial roles more attractive.

\section{Emotions and psychological biasing}

The distinction between task-oriented roles (typified by middle leaders) versus relationshiporientated roles (teachers and headteachers) presented in Yukl's taxonomy appears to closely parallel the distinction made between social and mechanical tasks.

For example, at the individual level, task-orientated leaders were said to have a high need for achievement (Henkel et al., 2019). Indvik (1986) pointed out that often achievement-orientated leaders were cold and aloof, signalling their preference for psychological distance from followers (Blau and Scott, 1962). This is supported by advances in neuroscience with evidence that task-orientated activities trigger a range of regions of the brain, typically grouped under the heading of task-positive network (TPN). Whereas, relationship-orientated activities operate different regions of the brain under the term default mode network (DMN). Roy et al. (2012) states that the primary functions of the DMN circuits are self-related processing, autobiographical memory and perception, cognitive representation of emotion, representation of value/reward, emotion selfregulation and autonomic processing. Shulmanetal (1997a, b); (Duncan and Owen, 2000); Fox et al. (2005); Owen et al.(2005) and Van Overwalle (2011) all agree that the TPN is associated with a wide variety of non-social tasks including those involving focussed attention, working memory, language, logical reasoning, mathematical reasoning and causal/mechanical reasoning.

Fox et al. (2005) highlight the anti-correlation between these two networks. Stating that when TPN is activated, DMN is subsequently deactivated. This suggests that when a leader is focussed on a task-orientated role, their ability and desire to attend to the relationship needs of their followers is diminished. This is not to say that leaders cannot be both highly analytical and to build effective relationships. In the absence of any task, it is known that the human brain naturally cycles between activation of the TPN and activation of the DMN, triggering each several times in a minute (Fox et al., 2005).

This reinforces the point that leadership is more complex than simply a leadership theory or being able to recognise emotions. While both are important we cannot 
underestimate the role in which the brain plays in subconsciously switching functional nodes on and off to better facilitate the range of leadership activities that are required of individuals.

\section{Methodology}

The objective of this paper was to examine the extent to which those who work in education can recognise emotions. The sampling unit was schools in England. Eighty-three individuals from a range of schools (primary and secondary) participated in an emotional recognition test (ERT). Participants were self-selecting through emails to schools based on a convenience sample (Plowright, 2011) and held a variety of roles within from teachers, head of department, assistant or deputy headteacher and headteacher. Access to the survey was only distributed to individuals who expressed some form of interest in participating in this exploratory study emotions.

An important point to note is that the number of respondents is small, 83. This was deliberately done to get a set of data from which to explore whether there are any differences in individuals' ability to recognise emotion and whether a further larger study should be conducted. This initial study would provide details of whether a larger scale study should be conducted. It is also worth noting that while the findings of this study as this stage may not be generalisable due to the limitations of sample size.

All participants completed the Geneva Emotion Recognition Test (GERT) to identify their levels of ER. This particular test was used as it provides a larger number of emotions for participants to select from. The GERT test consists of 14 emotions (six positive and eight negative), portrayed by 10 actors (five men and five women) of different ages who depict these emotions in short audio-video clips (dynamic multimodal stimuli). Unlike other ERTs which commonly use either 5 (Scherer and Scherer, 2011), 7 (Matsumoto et al., 2000) or 10 (Bänziger et al., 2009) emotions, the GERT system uses 14 emotions affording greater flexibility in emotion choice than classical test theory. This reduces the chances of consistency motif whereby a consistency propensity between participants is sought (Podsakoff et al., 2003).

Hall et al. (2009) found that sensitivity in social interactions (encompassing an individual's ability to successfully infer and interpret another person's emotions) is positively correlated with social skills, the ability to adjust to new or foreign cultures, effectiveness in the workplace and the quality of relationships that can be built. With regards to EI, Mayer et al. (2000) have suggested that ER is an elementary part of the ability EI model.

\section{Findings and discussion}

The preliminary data set comprised 83 individuals, $54 \%$ of the participants were female $(n=45)$ and $46 \%$ were male $(n=38)$, the mean average age of participants was 37.4 years and individuals had spent an average of 5.5 years within their current role.

Table 2 shows the average percentage of correctly recognised emotions (ER score) of classroom teachers was $42.53 \%$, based on a sample of 42 . The confidence interval (at $95 \%$ ) for the population mean of all teacher would be between 41.31 and 43.75 . This suggests that

\begin{tabular}{lcc}
\hline Organisational role & Number participating & Average score \\
\hline Teachers & 42 & $42.53 \%$ \\
Middle leaders & 23 & $21.57 \%$ \\
Senior leaders & 11 & $38.31 \%$ \\
Headteacher & 7 & $46.59 \%$
\end{tabular}

Table 2. Response scores by organisational role 
JWAM

12,2

\section{8}

individuals are able to differentiate between a greater range of emotions, such as a blend of more complex emotions. This relates to level 4/5 on the Subic-Wrana et al. (2011) model of the LEA. A total of 23 heads of departments (middle leaders) took part in the study and their score was significantly lower than any other groups within the study, with an average score of only $21.57 \%$. They were less able to recognise complex emotions but were able to successfully identify single emotions (level 3 of the LEA model). The average score of the Deputy and Assistant Heads group was $38.31 \%$ - still lower than the classroom teachers (Figure 1). Despite there only being seven headteachers who participated in the study, they had an average score of $46.59 \%, a+4 \%$ difference from classroom teachers. Additionally, there was a statistically significant difference between groups as determined by one-way ANOVA $(F(3,16)=2,899, p=0.00001)$. However, all participants of this study scored lower than members of the public, scoring an average of $67 \%$, (Schlegel et al., 2014).

Initially, the average score of education practitioners lessens as classroom teachers move into instructional [middle] leadership roles (the data suggest that the average ER scores halve to $21.57 \%$ ). As middle leaders move into more senior positions, Assistant Headteacher and Deputy Headteacher roles, their score improves. Further improving as they move into Headteacher roles. If the scores of those entering the profession are similar to those at the top of the organisational hierarchy, then it is possible that it is not the individual's ER ability which changes. Instead, the combination of external influences (outside of an individual's control), and internal demands including the expectations placed on instructional leaders act as contributory factors in the reduction in test scores. This suggests that individuals can move between levels within Subic-Wrana et al. (2011) model rather than is being a linear progression as previously suggested.

Research by Brown et al. (2000) states that a major problem facing middle leaders is a lack of time to complete all of the managerial tasks in addition to the responsibilities they have towards their own lessons. Middle leaders, as the title suggests, are sandwiched between those working in the senior leadership team (SLT) and their colleagues, and sometimes former peers, within their departments. A sense of loyalty to both, or either of these groups, may compound the difficulties that middle leaders face.

McKinney et al. (2013) suggested that middle leaders are overloaded with work, undertrained and on the edge of burning out. It is the lack of training that Constable and McCormick (1987) note, suggesting that a majority of individuals entering management

Figure 1.

Results of the GERT categorised by functional role

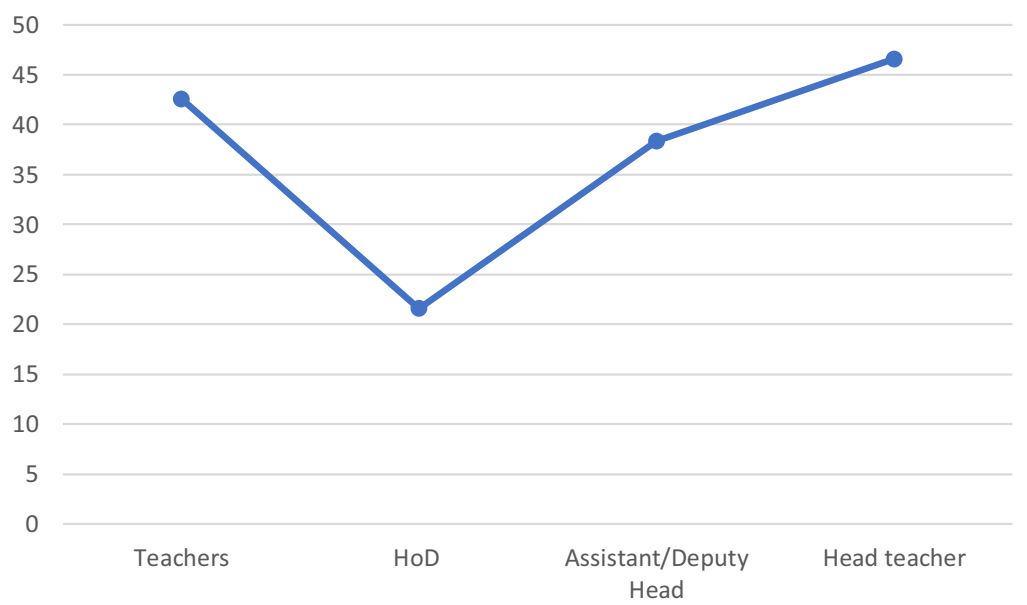


positions have little in the way of training. Turner and Bolam (1998) pointed out that middle leaders do have room for manoeuvre and will proactively conceptualise their role and not merely act as a conduit through which the decisions of the SLT will be communicated. At the same time, research by Brown et al. (2000) showed that middle leaders are unsatisfied with having to subordinate their vision in favour of that of senior staff members, and their departmental vision was often undervalued, and their professional judgment insufficiently recognised by senior managers, governors and external bodies.

Kubit and Jack (2013) state that it is possible to switch between networks and possible roles. However, they go onto suggest that leaders cannot simultaneously attend to these two distinct roles, hence conflicts are likely to arise if leaders get "stuck" in one role. The prolonged suppression of one of the networks and associated roles subsequently decreases an individual's ability to switch between the two networks. Some scholars have noted this tradeoff. For example, Yukl (2008) notes that "efforts to improve one performance determinant may have an adverse effect on another performance determinant. When leaders are preoccupied with responding to external threats (task), there is less time for people-oriented concerns such as being supportive and developing member skills" (pp. 711-714).

Given the task-orientated nature of the middle leader role, it is unsurprising that their level of emotional recognition has diminished. However, it appears to increase again as individuals move into more relationship-orientated roles as senior leaders (assistant- and deputy headteacher) when the level of TDM is likely to reduce and the normal cycling between TDM and DMN is restored. This is evidence in the results of this study which found that those individuals in more senior roles and which were relationship-orientated were better able to recognise emotions.

One possible solution would be the differentiating the leadership role. For example, having a role such as middle leadership which is predominantly positioned within one neural state (TPN) allows a leader to spend the majority of their time in one of the two neural networks (TPN or DMN) and reduces the need to cycle between them. Yet traversing between the two networks is associated with good mental health and higher intelligence quotient. Whereas a lessening of the cycling between networks could potentially increase an individuals susceptibility to a variety of mental health disorders, as described by Andrews-Hanna et al. (2010); Anticevic et al. (2012); Whitfield-Gabrieli and Ford (2012), including what Broyd et al. (2009) describes as a power-stress syndrome.

A more effective approach would be to train and develop leaders so that they possess a higher level of competency in enacting both the task and relationship leadership roles, alongside the ability to switch between them. This needs to be done with an awareness of appropriate cues and contexts for doing so. While the actions to invoke a change of role are within a leader's purview, where this is not possible they might be able to ensure that time and space is created for individuals to transverse between the two associated networks. For example, where a leader who is heavily into a task-orientated role (and therefore TPN activation) they could, for example, each day coach another person within the organisation. By deciding to and committing to coach a person each day, either formally or informally, over coffee or lunch, the leader commits to switching into the relationship role at least once a day and thus activating the DMN in both themselves and the other person. Over time and practice, the switching between the task and relationship roles would likely become easier and help the leader develop more cues as to when one role is more appropriate or possible than the other.

\section{Conclusion}

While the idea that a task can be classified as either analytical or social is useful for theoretical purposes as with most dichotomies is an oversimplification and rarely as clear-cut in practice. 
JWAM

12,2
In reality, and particularly in leadership, all tasks have both a relational component and an analytical component. Therefore, the greater ability a leader has to switch between these two modes of reasoning the more effective they will be as a leader. We suspect that minimising the suppression of the opposing network will make it easier, faster and less costly for the leader to switch between the two networks. The ability to switch between the two opposing networks may require a reduction in the intensity of the dominant network to facilitate leaders in making the switch between modes easier.

In this paper, we explored the challenges that middle leaders experience in recognising emotions. It would appear that this is a temporary loss which is most probably as a result of the task-orientated nature of being a middle leader. While one could posit that this is purely a situation which arises because of the disposition of the middle leadership role, it transpires that this is complicated by the brains' inability to function effectively in both task- and relationship-orientated modes.

To minimise the unresolved tension that leaders face in developing their roles to attend to both the task requirements and the relationship requirements as a result of the antagonism between the TPN and the DMN. This paper proposes that middle leaders should make a conscious effort to function in the DMN mode, which could be achieved by coaching a member of staff.

What is clear that further work is needed to ascertain whether this is unique to education or whether those in middle leadership roles in other sectors experience the shame challenges in recognising emotions, based on position within the organisational hierarchy. Also, the question as to how the emotionless middle leader impacts others within teams that they lead needs addressing.

\section{References}

Andrews-Hanna, J.R., Reidler, J.S., Sepulcre, J., Poulin, R. and Buckner, R.L. (2010), "Functionalanatomic fractionation of the brain's default network", Neuron, Vol. 65, pp. 550-562.

Anticevic, A., Cole, M.W., Murray, J.D., Corlett, P.R., Wang, X.J. and Krystal, J.H. (2012), "The role of default network deactivation in cognition and disease", Trends in Cognitive Sciences, Vol. 16, pp. 584-592.

Ashkanasy, N.M. and Dasborough, M.T. (2003), "Emotional awareness and emotional intelligence in leadership teaching", Journal of Education for Business, Vol. 79, pp. 18-22.

Bales, R.F. (1958), "Task roles and social roles in problem-solving groups", in Maccoby, E., Newcomb, T. and Hartley, E. (Eds), Readings in Social Psychology, Rinehart and Winston, New York, NY, pp. 437-447.

Bass, B. (1990), "From transactional to transformational leadership: learning to share the vision", Organizational Dynamics, Vol. 18 No. 3, pp. 19-31.

Blau, P. and Scott, W. (1962), Formal Organizations, Chandler, San Francisco, CA.

Brown, M., Rutherford, D. and Boyle, B. (2000), "Leadership for school improvement: the role of the head of department in UK secondary schools", School Effectiveness and School Improvement, Vol. 11 No. 2, pp. 237-258.

Broyd, S.J., Demanuele, C., Debener, S., Helps, S.K., James, C.J. and Sonuga-Barke, E.J.S. (2009), "Default-mode brain dysfunction in mental disorders: a systematic review", Neuroscience and Biobehavioral Reviews, Vol. 33 No. 3, pp. 279-296.

Bush, T. (2007), "Educational leadership and management: theory, policy, and practice", South African Journal of Education, Vol. 27 No. 3, pp. 391-406.

Canter, N. and Kihlstrom, J.F. (1987), Personality and Social Intelligence, Prentice-Hall, New Jersey.

Cheese, P. (2008), "Talent a prerequisite for high performing companies", Management Today, March 2008, Chartered Management Institute, London, pp. 38-42. 
Constable, J. and McCormick, R. (1987), The Making of British Managers, CBI /BIM, London.

Davies, B. and Davies, B.J. (2008), Developing Strategic Leadership, Secondary Leadership Paper -31, NAHT published paper, West Sussex.

Davies, B. and Davies, B.J. (2011), Leading the Strategically Focused School: Success and Sustainability, SAGE Publications, New York.

Duncan, J. and Owen, A.M. (2000), "Common regions of the human frontal lobe recruited by diverse cognitive demands", Trends in Neurosciences, Vol. 23, pp. 475-483.

Fox, M.D., Snyder, A.Z., Vincent, J.L., Corbetta, M., Van Essen, D.C. and Raichle, M.E. (2005), "The human brain is intrinsically organized into dynamic, anticorrelated functional networks", Proceedings of the National Academy of Sciences, Vol. 102 No. 27, pp. 9673-9678.

Frearson, M. (2003), Tomorrow's Learning Leaders, Learning and Skills Network, London.

Gardner, H. (1983), Frames of Mind: The Theory of Multiple Intelligences, Basic Books, New York.

Goleman, D., Boyzatzis, R. and Mckee, A. (2013), Primal Leadership: Realizing the Power of Emotional Intelligence, Harvard Business Press, Harvard.

Grobler, P.A. and Diedericks, H. (2008), "Talent management: an empirical study of selected South African hotel groups", available at: http://www.unisa.ac.za/contents/faculties/service_dept/ docs/talent_man_3_CHAPTER1.pdf (accessed 31 December 2019).

Gronn, P. (2003), The New Work of Educational Leaders: Changing Leadership Practice in an Era of School Reform, Paul Chapman, London.

Gronn, P. and Lucey, K. (2006), "Cloning their own: aspirant principals and the school-based selection game”, Australian Journal of Education, Vol. 50, pp. 102-21.

Hall, J.A., Andrzejewski, S.A. and Yopchick, J.E. (2009), "Psychosocial correlates of interpersonal sensitivity: a meta-analysis", Journal of Nonverbal Behaviour, Vol. 33, pp. 149-180.

Hargreaves, A. and Fink, D. (2008), Sustainable Leadership, Wiley and Sons, New York.

Hays (2014), "Career progression in teaching: what's driving UK educators? The Guardian", [Online] available at: http://www.theguardian.com/teacher-network/teacher-blog/interactive/2014/apr/ 29/career-progression-teaching-uk-educators-education (accessed 7 April 2019).

Henkel, T.G., Marion, J.W. and Bourdeau, D.T. (2019), "Project management leadership behaviour: task-orientated versus relationship-orientated", Journal of Leadership Education, Vol. 18 No. 2, pp. 1-14.

Hughes, M., Patterson, L. and Terrell, J. (2005), Emotional Intelligence in Action: Training and Coaching Activities for Leaders and Managers, John Wiley and Sons, New Jersey.

Indvik, J. (1986), "Path-goal theory of leadership: a meta-analysis", Academy of Management, Vol. 1, pp. 189-192.

Jago, G. (1982), "Leadership: perspectives in theory and research", Management Science, Vol. 28 No. 3, pp. 221-339.

Kubit, B. and Jack, A.I. (2013), "Rethinking the role of the rTPJ in attention and social cognition in light of the opposing domains hypothesis: findings from an ALE-based meta-analysis and resting-state functional connectivity", Frontiers in Human Neuroscience, Vol. 7, p. 323.

Lane, R.D., Sechrest, L., Riedel, R., Weldon, V., Kaszniak, A.W. and Schwartz, G.E. (1996), "Impaired verbal and nonverbal emotion recognition in alexithymia", Psychosomatic Medicine, Vol. 58, pp. 203-210.

Lynch, K., Grummell, B., Devine, D. (2012), New Managerialism in Education Commercialization, Carelessness and Gender, Palgrave Macmillan, London.

Madhar, M. (2010), Emotional Intelligence of Teachers and Effective Class Room Management, College of Applied Science, Oman.

Matsumoto, D., LeRoux, J., Wilson-Cohn, C., Raroque, J., Kooken, K., Ekman, P., Yrizarry, N., Loewinger, S., Uchida, H., Lee, A., Amo, L. and Goh, A. (2000), "A new test to measure emotion 
JWAM

12,2 recognition ability: matsumoto and Ekman's Japanese and Caucasian Brief Affect Recognition Test (JACBART)", Journal of Nonverbal Behaviour, Vol. 24, pp. 179-209.

Mayer, J.D. and Salovey, P. (1997), "What is emotional intelligence?", in Salovey, P. and Sluyter, D. (Eds), Emotional Development and Emotional Intelligence: Implications for Educators, Basic Books, New York.

Mayer, J.D., Salovey, P., Caruso, D.L. and Sitarenios, G. (2000), "Measuring emotional intelligence with the MSCEIT V2. 0", Emotion, Vol. 3, pp. 97-105.

Mayer, J.D., Salovey, P., Caruso, D.L. and Sitarenios, G. (2001), "Emotional intelligence as a standard intelligence", Emotion, Vol. 1, pp. 232-242.

McClelland, D. (1961), The Achieving Society, Van Nostrand, Princeton, NJ.

McKinney, R., McMahon, M. and Walsh, P. (2013), "Danger in the middle: why midlevel managers aren't ready to lead", available at: http://www.harvardbusiness.org/sites/default/files/PDF/ 17807_CL_MiddleManagers_White_Paper_March2013.pdf (accessed 8 April 2019).

Meisler, G. (2010), "Employee with higher level of emotional intelligence is more dedicated and satisfied at work", University of Haifa, available at: http://www.physorg.com/news203761527. html (accessed 29 December 2019).

Mortiboys, A. (2005), Teaching with Emotional Intelligence: A Step-by-step Guide for Higher and Further Education Professionals, Routledge, New York.

Mortiboys, A. (2012), Teaching with Emotional Intelligence: A Step by Step Guide for Higher and Further Education Professionals, 2nd ed., Routledge, New York.

Owen, A.M., McMillan, K.M., Laird, A.R. and Bullmore, E. (2005), "N-backworking memory paradigm: a meta-analysis of normative functional neuroimaging studies", Human Brain Mapping, Vol. 25, pp. 46-59.

Paul, D.B. (2005), "Talent management. SHRM white paper. SHRM information center", [Online] available at: www.shrm.org/hrresources/whitepapers-published/CMS014491 (accessed 31 December 2019).

Plowright, D. (2011), Using Mixed Methods: Frameworks for an Integrated Methodology, SAGE Publishing, London.

Podsakoff, N., MacKenzie, S., Lee, J.Y. and Podsakoff, N. (2003), "Common method biases in behavioral research: a critical review of the literature and recommended remedies", Journal of Applied Psychology, Vol. 88 No. 5, pp. 879-903.

Powell, W. and Kusuma-Powell, O. (2010), Becoming an Emotionally Intelligent Teacher, Corwin, Thousand Oaks, CA.

Roy, M., Shohamy, D. and Wager, T.D. (2012), "Ventromedial prefrontal-subcortical systems and the generation of affective meaning", Trends in Cognitive Sciences, Vol. 16, pp. 147-156.

Sani, N.B. (2009), The Influence of Efficacy and Emotional Intelligence of Technical Secondary School Administrators and Teacher's Professional Collaboration on Teacher's Job Satisfaction, Doctoral Thesis, University Ultara Malaysia, Malaysia.

Scherer, K. and Scherer, U. (2011), "Assessing the ability to recognize facial and vocal expressions of emotions: construction and validation of the Emotion Recognition Index (ERI)", Journal of Nonverbal Behavior, Vol. 35, pp. 305-326.

Schlegel, K., Grandjean, D. and Scherer, K. (2014), "Introducing the Geneva emotion recognition test: an example of rasch-based test development”, Psychological Assessment, Vol. 26 No. 2, pp. 624-647.

Schunk, D. and Zimmerman, B. (1998), Self-regulated Learning: From Teaching to Self-Reflective Practice, Guildford Press, New York.

Shulman, G.L., Corbetta, M., Buckner, R.L., Fiez, J.A., Miezin, F.M. and Raichle, M.E. (1997a), “Common blood flow changes across visual tasks: I. Increases in subcortical structures and cerebellum but not in non-visual cortex", Journal of Cognitive Neuroscience, Vol. 9, pp. 624-647. 
Shulman, G.L., Corbetta, M., Buckner, R.L., Fiez, J.A., Miezin, F.M. and Raichle, M.E. (1997b), “Common blood flow changes across visual tasks: II. Decreases in cerebral cortex", Journal of Cognitive Neuroscience, Vol. 9, pp. 648-663.

Silva, A. (2016), "What is leadership?", Journal of Business Studies Quarterly, Vol. 8 No. 1, pp. 1-5.

Sternberg, R.J., Wagner, R.K., Williams, W.M. and Horvath, J.A. (1995), "Testing common sense", American Psychologist, Vol. 50 No. 12, pp. 912-927.

Stogdill, R.M. (1974), Handbook of Leadership: A Survey of Theory and Research, The Free Press, New York.

Subic-Wrana, C., Beutel, M.E., Garfield, D.A. and Lane, R.D. (2011), "Levels of emotional awareness: a model for conceptualizing and measuring emotion-centered structural change", The International Journal of Psychoanalysis, Vol. 92 No. 2, pp. 289-310.

Turner, C. and Bolam, R. (1998), "Analyzing the role of the head of department in secondary schools in England and Wales: towards a theoretical framework", School Leadership and Management, Vol. 18 No. 3, pp. 373-388.

Van Overwalle, F. (2011), "A dissociation between social mentalizing and general reasoning", NeuroImage, Vol. 54, pp. 1589-1599.

Vroom, V. and Jajo, G. (2007), “The role of the situation in leadership”, American Psychologist, Vol. 62 No. 1, pp. 17-24.

Wakeman, C. (2009), "Emotional intelligence: towards a generic framework for the 21st century", Educational Futures, Staffordshire University, Vol. 2 No. 1, pp. 40-56.

Wall, T., Russell, J. and Moore, N. (2017), "Positive emotion in workplace impact: the case of a workbased learning project utilising appreciative inquiry", Journal of Work-Applied Management, Vol. 9 No. 2, pp. 129-146.

Whitfield-Gabrieli, S. and Ford, J.M. (2012), "Default mode network activity and connectivity in psychopathology", Annual Review of Clinical Psychology, Vol. 1 No. 8, pp. 49-76.

Wofford, J.C. (1970), "Factor analysis of managerial behavior variables", Journal of Applied Psychology, Vol. 54 No. 2, pp. 169-173.

Yukl, G. (2008), "How leaders influence organizational effectiveness", The Leadership Quarterly, Vol. 19, pp. 708-722.

Zeidner, M., Matthews, G. and Roberts, R.D. (2004), "Emotional intelligence in the workplace: a critical review”, Applied Psychology, Vol. 53 No. 3, pp. 371-399.

\section{Further reading}

Banziger, T., Grandjean, D. and Scherer, K.R. (2009), "Emotion recognition from expressions in face, voice, and body: the Multimodal Emotion Recognition Test (MERT)", Emotion, Vol. 9, pp. 691-704.

Cawley, W.H. (1928), "Three distinctions in the study of leaders", The Journal of Abnormal and Social Psychology, Vol. 23 No. 2, pp. 144-157.

Fleishman, E.A. (1953), "Leadership climate, human relations training, and supervisory behavior", Personnel Psychology, Vol. 6, pp. 205-222.

\section{Corresponding author}

Steve Lambert can be contacted at: s.lambert@chester.ac.uk

For instructions on how to order reprints of this article, please visit our website:

www.emeraldgrouppublishing.com/licensing/reprints.htm

Or contact us for further details: permissions@emeraldinsight.com 